\title{
Antioxidant Activity and Phytochemical Compounds of Capsicum annuum L. ${ }^{+}$
}

\author{
Raluca SUICA-BUNGHEZ 1, Lorena IANCU 1,2,* and Rodica-Mariana ION 1,2 \\ 1 The National Institute for Research \& Development in Chemistry and Petrochemistry, 060021 Bucharest, \\ Romania; raluca_bunghez@yahoo.com (R.S.-B.); rodica_ion2000@yahoo.co.uk (R.-M.I.) \\ 2 Valahia University of Targoviste, 130024 Targoviste, Romania \\ * Correspondence: lorena.iancu@icechim.ro \\ + Presented at the 15th International Symposium "Priorities of Chemistry for a Sustainable Development" \\ PRIOCHEM, Bucharest, Romania, 30th October-1st November 2019.
}

Published: 14 October 2019

Keywords: antioxidant activity; phytochemical compounds; Capsicum annuum L.

The benefits of Capsicum annuum L. are important for human health with its anti-inflammatory and analgesic properties in the case of stomach and back pain, muscle spasms, headaches, skin aging, peptic ulcers [1]. The aim of the present study was to characterize and investigate the antioxidant activity and phytochemical compounds [2] of three types (red, yellow, green) of hot pepper (Capsicum annuum L.) samples, using two methods of extract production (maceration and ultrasound).

In this research, we presented the results in the field of antioxidant activity and phytochemical analysis, using extracts obtained from three types of pepper native plants (red, yellow and green) extracted using two methods (maceration-M and ultrasound-U) in ethanol (EtOH) or methanol $(\mathrm{MeOH})$ solvents. The sample extracts were studied using UV-VIS and TLC techniques. The antioxidant property was determined using DPPH method [3], Figure 1.
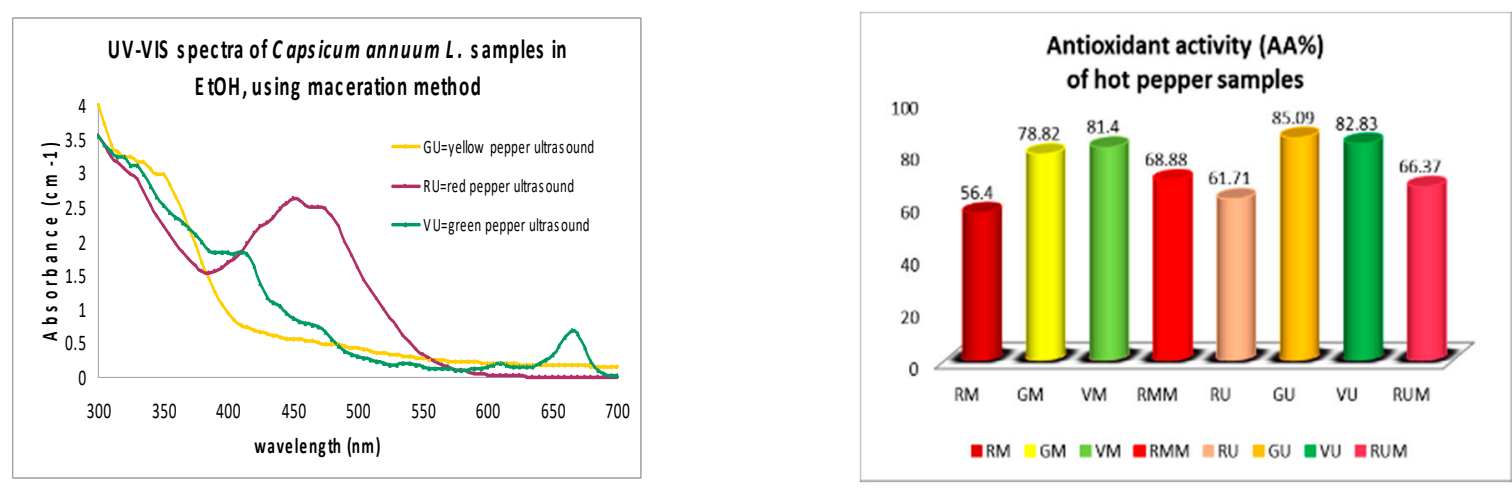

Figure 1. UV-VIS spectrum of Capsicum annuum L. and graph of the antioxidant activities (AA \%) values for hot pepper samples.

For the maceration method in EtOH, the samples codifications are: GM-yellow hot pepper maceration in $\mathrm{EtOH}, \mathrm{VM}$-maceration in $\mathrm{EtOH}, \mathrm{RM}$ - red hot pepper maceration in EtOH, RMM red hot pepper maceration in $\mathrm{MeOH}$. Ultrasound method: $\mathrm{GU}-$ ultrasound yellow hot pepper in $\mathrm{EtOH}, \mathrm{VU}-$ ultrasound green hot pepper in $\mathrm{EtOH}, \mathrm{RU}-$ ultrasound red hot pepper in $\mathrm{EtOH}$, RUM-ultrasound red hot pepper in $\mathrm{MeOH}$. 
Red, yellow and green pepper extracts have a very high antioxidant activity (AA \%), which denotes the benefits of the compounds existing in these vegetables. The ultrasound method revealed higher values compared to maceration. The color of the peppers is due to the presence of carotenoids, as demonstrated by the UV-VIS spectrum measurements. In the case of the yellow pepper extract $(\mathrm{GM})$, the carotenoids are found in the range $325-425 \mathrm{~nm}$. In red peppers (RM), $\beta$-carotenoid peak is found between $445-478 \mathrm{~nm}$, which is more pronounced using ultrasound method. Hot pepper samples extracted in ethanol, using maceration method (RM, GM, VM), present higher values of flavonoids (TFC), compared to the samples extracted in the same solvent (ethanol), but using the ultrasound method (RU, GU, VU). In the case of terpenoids (TTpC), it was observed that the extracts of green pepper (VM and VU), obtained by both methods ( $\mathrm{M}$ and $\mathrm{U}$ ), have the highest values.

Acknowledgments: This work was supported by a NUCLEU Program, conducted with MCI support, project number PN.19.23.03.01.04.

Conflicts of Interest: Authors declare no conflict of interest.

\section{References}

1. Ilie, M.A.; Caruntu, C.; Tampa, M.; Georgescu, S.R.; Matei, C.; Negrei, C.; Ion, R.M.; Constantin, C.; Neagu, M.; Boda, D. Capsaicin: Physicochemical properties, cutaneous reactions and potential applications in painful and inflammatory conditions. Exp. Ther. Med. 2019, 18, 916-925.

2. Suica-Bunghez, I.R.; Teodorescu, S.; Bucurica, I.A.; Somoghi, R.; Ion, R.M. Characterization of antioxidant activity and phytochemical compounds, metal nanoparticles obtained by Sideritis Scardica extracts. Rev. Roum. Chim. 2017, 62, 545-552.

3. Suica-Bunghez, I.R.; Barbinta-Patrascu, M.E.; Dumitrescu, O.; Ungureanu, C.; Fierascu, I.; Iordache, S.M.; Ion, R.M. Environmentally friendly phytosynthesis of silver-based materials using Cornus mas L. Fruits. Environ. Eng. Manag. J. 2016, 15, 2085-2094.

(C) 2019 by the authors. Licensee MDPI, Basel, Switzerland. This article is an open access article distributed under the terms and conditions of the Creative Commons Attribution (CC BY) license (http://creativecommons.org/licenses/by/4.0/). 